\title{
Nutrition lessons improve Hispanic teenage girls' knowledge
}

Michelle R. Neyman a Gladys Block J Jennifer L. Morris D Sheri Zidenberg-Cherr

\begin{abstract}
Nutrition knowledge and dietary intake among Hispanic teenage girls were assessed before and after a nutrition education intervention. We found that subjects were consuming several important nutrients at levels below current government recommendations. On average, Hispanic teenage girls consumed folate, calcium, zinc and iron at levels that were $40 \%, 36 \%, 18 \%$ and $8 \%$ below current recommendations, respectively. Participation in the fivelesson nutrition education program resulted in a $50 \%$ increase in nutrition knowledge and modest changes in dietary behavior; we observed improved dietary intake of vitamin C. Long-term interventions are needed to improve dietary habits as one means of enhancing overall health.
\end{abstract}

Although Hispanics are the secondlargest minority population in the United States, relatively little is known about their current health and nutritional status. Literature on Hispanic food habits, dietary intake and nutritional status is scattered and of variable content and quality. This is a critical issue in California; currently, the state's population is about $29 \%$ Hispanic, and is expected to rise to $38 \%$ by 2020 . In addition, about $22 \%$ of those living below the poverty level in California are Hispanic. Poverty is one of the many risk factors that place individuals at risk for health and nutrition problems (Hall and Richards 1995). Hispanic adolescents may be at particular risk for nutritional inadequacy. Limited information suggests

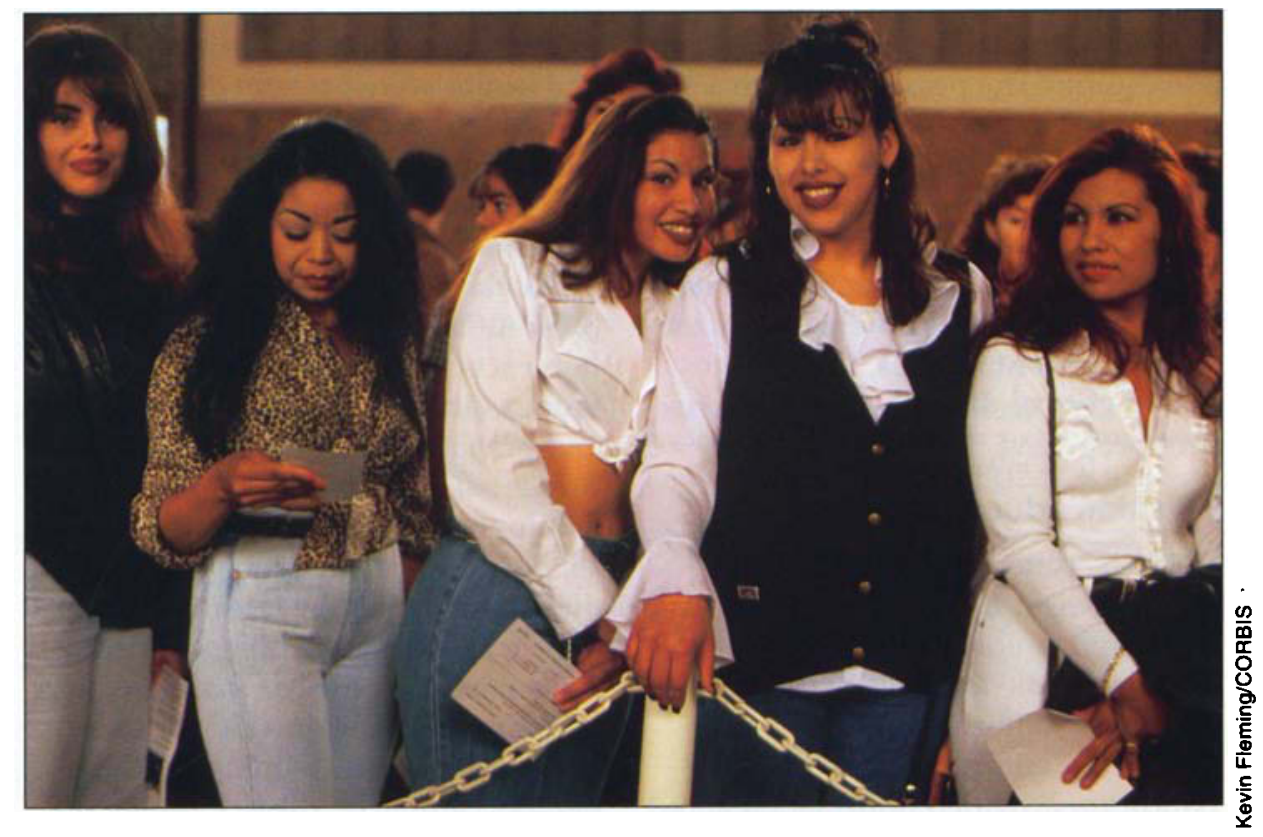

California's Hispanic population is expected to rise to $38 \%$ by 2020 . Hispanic adolescents may be at particular risk for nutritional inadequacy.

that their diets are often low in the nutrients folate, calcium, iron and zinc (LSRO 1995; Fanelli-Kuczmarski and Wotecki 1990; Looker et al. 1993).

In Fresno County, an agricultural area, the prevalence of healthful dietary behaviors among white and Mexican-American adults was reported to be low (DiSogra et al. 1994). Specifically, $12 \%$ of the Hispanics studied reported consuming no fruits or vegetables on the previous day. The investigators concluded that even in a county with high availability of fresh produce, fruit and vegetable consumption was below current recommendations, especially in the MexicanAmerican population. DiSogra and colleagues suggested that communitybased intervention programs, includ- ing nutrition education, are needed to improve awareness, motivation and skills to change dietary patterns (DiSogra et al. 1994).

The U.S. Department of Health and Human Services Report of the Secretary's Task Force on Black and Minority Health emphasized the need for special attention to chronic health problems among minorities whose average annual incomes are lower than those of white persons in the United States (USDHHS 1985). For example, Hispanics in California experience a relatively high incidence of neuraltube defects (CBDMP 1994). However, low-quality diets are not restricted to individuals with low socioeconomic status; many teenagers also eat poorly, regardless of economic status (LSRO 
1995). Similarly, the diets of women who follow popular weight-loss programs are characterized by intakes of selected nutrients well below current recommendations.

Health problems caused by inadequate nutrient intakes and poor eating habits include iron deficiency anemia and an increased risk of diabetes, obesity, cardiovascular disease and neural-tube defects. Given the relationship of diet to overall health and well-being, we believe it is essential that nutrition education be provided to at-risk populations such as Hispanic adolescents. The primary objective of our study was to evaluate the nutrition knowledge and dietary intake of a group of Hispanic teenage girls. A second objective was to assess the effectiveness of a brief education program on nutrition knowledge and selected nutrient intakes, in order to obtain critical data for designing future programs.

\section{Nutrition education study}

We recruited Hispanic teenage girls, between 13 and 18 years old $(n=$ 184), from junior and senior high schools in Yolo and Solano counties of Northern California. Prior to recruitment, the California Department of Education provided information about the age, ethnicity and parental socioeconomic status of students attending schools in the greater Sacramento area. Schools with the highest proportion of Hispanics in low-income families were used as recruitment sites. Subjects were recruited through their sciencerelated courses, and were excluded from participation if they reported being pregnant. Because recruitment took place in classrooms with varying ethnicities and races, non-Hispanic teenage girls were also invited to participate. Depending on the preferences of the school principals, young women were either paid $\$ 10$ or invited to a luncheon after completion of the study. All procedures were reviewed and approved by the Committee on the Use of Human Subjects at UC Davis.

The study design included a pretest interview, followed by intervention (nutrition education lessons) and a post-test interview. Following recruitment, informed parental consent was obtained for subjects under 18 years; those over 18 gave their own written consent. Students received an in-person, pretest interview that included questions about demographics and nutrition knowledge. Dietary intake was assessed by means of a 24-hour dietary recall administered by a trained interviewer. Two additional 24-hour recalls were obtained by telephone within the next 10 days. Approximately 1 week after the pretest, five 50 -minute lessons on nutrition and health were presented once a week for 5 weeks to half of the sample (education group, $n=96$ ), with an emphasis on using the Dietary Guidelines for Americans (USDA/USDHHS 1995), the Food Guide Pyramid (USDA/USDHHS 1992) and the Nutrition Facts food label to make healthy food choices. Information on nutrition and prenatal development was also presented.

We conducted the study during the 1995 spring and fall semesters. Immediately following the intervention, or 1 month following the pretest for control subjects, a post-test interview was administered. The nutrition knowledge post-test was administered in person. Similarly, dietary intake using a 24-hour recall was administered in person by a trained interviewer, with two additional 24-hour recalls by telephone.

Both qualitative and quantitative methods, including focus groups, interviews and field-testing of materials, were used in the development of the nutrition education lessons. The messages were tailored to the audience in order to increase effectiveness. Members of a similar target audience participated in selecting appropriate lesson format, content, illustrations and word choice. In addition to the education lessons, the nutrition knowledge and demographics questionnaires were field-tested among 128 eighthgrade science class students in Woodland and revised accordingly.

Assessment of dietary intake. The average of three 24-hour recalls was used to assess the subjects' recent nutrient intakes. Intakes on two week- days and one weekend day were obtained from each subject at pre- and post-test. Detailed probing was used to gather information on brand name, preparation methods and betweenmeal snacks of foods recalled. Portion size was estimated using a twodimensional food portion visual (Posner and Morgan 1992) and common household measuring cups, spoons and glasses. The nutrient composition of the dietary recalls was analyzed using Food Processor II software (ESHA Research, Salem, OR, version 2.1, 1988-1990). Nutrient intake from dietary supplements was not included in the analyses.

Two-tailed, paired $t$-tests were used to detect potential statistical differences in nutrition knowledge and dietary intake between pre- and posttest. Because there was a decrease in total calorie intake from pre- to posttest, we performed statistical analyses with computed nutrient densities.

Participant characteristics. Education and control subjects predominantly self-identified themselves as Hispanic. A majority of the remaining subjects identified themselves as Caucasian. Seventy-seven percent of control and $83 \%$ of education subjects reported being born in the United States; $17 \%$ and $15 \%$, respectively, reported Mexico as their place of birth. On average, education subjects were significantly older than control subjects ( 15.3 versus 14.8 years, respectively). Sixty percent of control and $69 \%$ of education subjects reported living with both parents. Approximately $30 \%$ of each group lived with one parent. Twentyeight percent of control and $42 \%$ of education subjects reported being employed outside of the home.

The primary language spoken at home was English for both groups. The next most frequently reported response was an equal amount of English and Spanish spoken at home. A small percentage, $7 \%$ among control and $6 \%$ among education subjects, reported "Spanish only" as the language spoken at home. The primary reading ability was "English better than Spanish" in both groups, and the primary writing ability was "only English" among the controls, and "English bet- 
ter than Spanish" among the education subjects. Most of the subjects reported that their parents were born in the United States or Mexico.

\section{Improvement in knowledge}

Nutrition knowledge. A 50\% increase in nutrition knowledge $(P<$ 0.0001 ) was observed in the education group, with no increase among the controls. For the control group, mean scores increased from 17.1 to 17.4 out of 41 possible points. For the education group, mean scores increased from 18.6 to 28.0 points. In addition to significant improvement from pre- to post-test in total score on the nutrition knowledge questionnaire, significant increases in nutrition knowledge were noted in each category of questions asked. Specifically, education subjects' nutrition knowledge significantly im- proved $(P<0.0001)$ in the areas of identifying food sources of selected nutrients, dietary guidelines and recommendations, physiologic functions of selected nutrients, developmental nutrition, and the relationship of diet to health and disease.

Dietary intake. Three-day mean intakes from 24-hour recalls obtained at pre- and post-test were used in the analyses of dietary intake. In terms of macronutrient composition, protein provided approximately $14 \%$ of energy in both groups, and dietary carbohydrate provided approximately $55 \%$ of energy (table 1). Dietary fat provided the remaining $31 \%$ of energy. No significant differences were noted between pre- and post-test, for control and education subjects.

Mean intakes of numerous nutrients were below current recommenda- tions for both groups at pre- and posttest (table 2). Folate intake was $40 \%$ below the recommended dietary allowance (RDA) of 300 and $400 \mu \mathrm{g}$ per day (for 9 to 13 years old and 14 to 18 years old, respectively) (IOM 2000a); calcium intake was $36 \%$ below the recommended intake (adequate intake) of $1,300 \mathrm{mg}$ (IOM 1999); iron intake was $8 \%$ below the RDA of $15 \mathrm{mg}$; zinc intake was $18 \%$ below the RDA of 12 mg (IOM 1989); and vitamin $E$ intake was $25 \%$ below the RDA of 11 and 15 $\mathrm{mg}$ /day (for 9 to 13 years old and 14 to 18 years old, respectively) (IOM 2000b).

When dietary intakes were calculated relative to current recommendations, many subjects consumed less than two-thirds of the recommended intake: $67 \%$ of subjects did not get enough folate in their diets; $62 \%$, of

TABLE 1. Three-day mean dietary intake of selected nutrients among Hispanic teenage girls in nutrition education study

\begin{tabular}{|c|c|c|c|c|c|}
\hline \multirow[b]{2}{*}{ Nutrient } & \multirow{2}{*}{$\begin{array}{l}\text { Recommended } \\
\text { intakes for girls }\end{array}$} & \multicolumn{2}{|c|}{ Control $(n=88)$} & \multicolumn{2}{|c|}{ Education $(n=96)$} \\
\hline & & Pretest & Post-test & Pretest & Post-test \\
\hline Energy (kcal) & & $2,052.0 \pm 66^{*}$ & $1,984.0 \pm 73$ & $2,060.0 \pm 62$ & $1,990.0 \pm 60$ \\
\hline Protein $(g)$ & & $70.4 \pm 2.6$ & $67.5 \pm 3.0$ & $70.5 \pm 2.5$ & $68.3 \pm 2.5$ \\
\hline Protein ( $\%$ total energy) & & $13.7 \pm 0.4$ & $13.6 \pm 0.4$ & $13.5 \pm 0.3$ & $13.6 \pm 0.3$ \\
\hline Carbohydrate (g) & & $282.8 \pm 9.1$ & $272.9 \pm 9.7$ & $289.9 \pm 8.4$ & $282.1 \pm 9.2$ \\
\hline Carbohydrate ( $\%$ total energy) & & $54.6 \pm 0.7$ & $54.8 \pm 0.8$ & $56.0 \pm 0.6$ & $55.8 \pm 0.7$ \\
\hline Fat $(g)$ & & $74.7 \pm 3.1$ & $72.6 \pm 3.6$ & $72.6 \pm 3.0$ & $68.8 \pm 2.6$ \\
\hline Fat ( $\%$ total energy) & & $31.6 \pm 0.6$ & $31.7 \pm 0.7$ & $30.4 \pm 0.6$ & $30.5 \pm 0.6$ \\
\hline Folate $(\mu \mathrm{g}) \dagger$ & $\begin{array}{r}300(13 \mathrm{yr} .) \\
400 \text { (14-18 yr.) }\end{array}$ & $230.4 \pm 11.1$ & $234.3 \pm 13.5$ & $238.5 \pm 12.3$ & $263.9 \pm 15.1$ \\
\hline Calcium $(\mathrm{mg}) \dagger$ & 1,300 (9-18 yr.) & $864.0 \pm 41.4 \mathrm{a}$ & $804.6 \pm 40.5 b$ & $874.1 \pm 38.5 a$ & $764.1 \pm 29.1 b$ \\
\hline Iron (mg) & 15 (11-18 yr.) & $13.1 \pm 0.5$ & $13.5 \pm 0.6$ & $14.5 \pm 0.6$ & $14.0 \pm 0.6$ \\
\hline Zinc (mg) & 12 (11-18 yr.) & $9.6 \pm 0.4$ & $9.3 \pm 0.5$ & $10.0 \pm 0.4$ & $10.3 \pm 0.4$ \\
\hline Vitamin A ( $\mu \mathrm{g} R E)$ & 800 (11-18 yr.) & $738.2 \pm 41.5$ & $874.2 \pm 63.8$ & $841.9 \pm 72.6$ & $874.4 \pm 62.7$ \\
\hline Vitamin C (mg) & $\begin{array}{l}45 \text { (11-14 yr.) } \\
65 \text { (15-18 yr.) }\end{array}$ & $108.7 \pm 7.9$ & $106.7 \pm 8.6$ & $108.2 \pm 6.8$ & $123.8 \pm 8.1$ \\
\hline Vitamin E (mg) & $\begin{array}{r}11 \text { (9-13 yr.) } \\
15 \text { (14-18 yr.) }\end{array}$ & $5.5 \pm 0.3$ & $6.4 \pm 0.8$ & $6.0 \pm 0.4$ & $6.1 \pm 0.6$ \\
\hline
\end{tabular}

Mean \pm standard error. Within a row, values sharing a common letter or without a letter are not significantly different $(P<0.05)$.

†Mean intakes less than two-thirds of the recommended intake.

TABLE 2. Nutrient densities (amount per 1,000 Kcals) for 3-day mean dietary intake of selected nutrients by Hispanic teenage girls in nutrition education study

\begin{tabular}{|c|c|c|c|c|c|}
\hline \multirow[b]{2}{*}{ Nutrient } & \multirow{2}{*}{$\begin{array}{l}\text { Recommended } \\
\text { intakes for girls }\end{array}$} & \multicolumn{2}{|c|}{ Control $(n=88)$} & \multicolumn{2}{|c|}{ Education $(n=96)$} \\
\hline & & Pretest & Post-test & Pretest & Post-test \\
\hline Protein $(\mathrm{g})$ & & $34.8 \pm 0.9^{*}$ & $34.4 \pm 1.0$ & $34.5 \pm 0.7$ & $34.6 \pm 0.8$ \\
\hline Carbohydrate (g) & & $138.9 \pm 1.8$ & $139.0 \pm 2.0$ & $142.4 \pm 1.7$ & $141.7 \pm 1.7$ \\
\hline Fat $(g)$ & & $35.6 \pm 0.7$ & $35.7 \pm 0.8$ & $34.4 \pm 0.6$ & $34.5 \pm 0.7$ \\
\hline Folate $(\mu \mathrm{g}) \dagger$ & $\begin{array}{r}300(13 \mathrm{yr} .) \\
400(14-18 \mathrm{yr} .)\end{array}$ & $116.4 \pm 5.4 \mathrm{a}$ & $120.4 \pm 6.4 \mathrm{ab}$ & $118.8 \pm 5.9 a b$ & $133.8 \pm 6.5 b$ \\
\hline Calcium (mg)† & 1,300 (9-18 yr.) & $424.4 \pm 15.2$ & $414.7 \pm 17.9$ & $430.0 \pm 14.5$ & $396.1 \pm 14.1$ \\
\hline Iron (mg) & 15 (11-18 yr.) & $6.6 \pm 0.2$ & $6.9 \pm 0.2$ & $7.2 \pm 0.3$ & $7.1 \pm 0.3$ \\
\hline Zinc (mg) & $12(11-18 \mathrm{yr})$. & $4.8 \pm 0.2 \mathrm{a}$ & $4.7 \pm 0.2 \mathrm{a}$ & $4.8 \pm 0.1 \mathrm{ab}$ & $5.2 \pm 0.2 b$ \\
\hline Vitamin A ( $\mu \mathrm{g}$ RE) & 800 RE (11-18 yr.) & $380.9 \pm 29.2 \mathrm{a}$ & $446.8 \pm 31.7 b$ & $411.7 \pm 32.0 \mathrm{a}$ & $450.9 \pm 29.6 b$ \\
\hline Vitamin C (mg) & $\begin{array}{l}45 \text { (11-14 yr.) } \\
65 \text { (15-18 yr.) }\end{array}$ & $54.1 \pm 3.8 \mathrm{a}$ & $56.9 \pm 4.6 \mathrm{ab}$ & $54.4 \pm 3.5 \mathrm{a}$ & $62.6 \pm 3.5 b$ \\
\hline Vitamin E (mg) & $\begin{array}{r}11 \text { (9-13 yr.) } \\
15 \text { (14-18 yr.) }\end{array}$ & $-\quad 2.7 \pm 0.1$ & $3.0 \pm 0.2$ & $2.9 \pm 0.2$ & $3.1 \pm 0.3$ \\
\hline
\end{tabular}

"Mean \pm standard error. Within a row, values sharing a common letter or without a letter are not significantly different $(\mathrm{P}<0.05)$.

†Mean intakes less than two-thirds of the recommended intake. 
calcium; $37 \%$, of zinc; and $28 \%$, of iron. Fifty-eight percent, $35 \%$ and $17 \%$ of subjects consumed less than twothirds of the recommended intake for vitamins $E, A$ and $C$, respectively.

Based on absolute nutrient intakes, we observed a significant decrease in calcium intake from pre- to post-test among the control and education groups. However, because the intake of total calories decreased from pre- to post-test, nutrient densities were calculated to take this change into account (table 2). After calculating nutrient densities, the decrease in calcium intake was no longer significant. In addition, there was a significant increase in vitamin $C$ intake $(P<0.05)$ from pre- to post-test in the education group, but not in controls. There was also a significant increase in vitamin $\mathrm{A}$ intake in both groups. Three-day mean 24-hour dietary intakes of protein, carbohydrate, fat, folate, iron, zinc and vitamin E, whether analyzed in absolute amounts or as nutrient densities, did not significantly change from pre- to post-test among control or education subjects. However, the increase in nutrient density of folate and zinc approached significance $(P=0.06)$ in the education group.

\section{Diet and health concerns}

The results of this study underscore the need to provide education to adolescents focusing on the importance of consuming diets adequate in essential nutrients. Our mean dietary intakes of micronutrients based on the multiple dietary recalls were similar to those reported in the Third National Health and Nutrition Examination Survey as well as the Continuing Survey of Food Intakes for Individuals 1989-90, for calcium, iron, zinc and vitamin $A$ (LSRO 1995). In all cases, the mean intakes failed to meet current recommendations, with the exception of pretest vitamin $A$ in the control group.

The Third Report on Nutrition Monitoring in the United States reported that from 1989 to 1991, lowincome adolescents had lower mean intakes of several vitamins and minerals than did adolescents from higherincome groups (LSRO 1995). Consistent with data from our study, these vitamins and minerals included vita- min A, vitamin C, vitamin B6, folate, calcium, iron and zinc.

Mean intakes of vitamin $\mathrm{E}$ in this sample of Hispanic teenage girls were lower than those reported previously (LSRO 1995). Epidemiological and clinical studies suggest that antioxidants in foods can lower the risk of chronic disease in later life, which suggests that higher intakes of antioxidant nutrients, such as vitamin E, should be encouraged (Halliwell 1996).

It is critical to educate young women about the benefits of making food choices consistent with the federal government's Dietary Guidelines for Americans (USDA/ USDHHS 1995), and increasing their consumption of foods rich in folate, calcium, iron and zinc. Although an adequate intake of most nutrients can be obtained from a wellbalanced, well-planned diet, such diets may not provide all nutrients at current recommended levels. Indeed, even if the Food Pyramid guidelines are used to plan a diet, it may be difficult to meet current recommended intakes for nutrients such as folate and zinc unless specific food choices are made (Keen and Zidenberg-Cherr 1994).

The nutrition lessons presented in this study produced a significant increase in knowledge, and produced modest effects on dietary behavior. The nutrition education intervention reported here was of short duration, so it is encouraging that the increase in nutrient density for folate and zinc approached significance from pre- to post-test in the education group ( $P=$ 0.06 ). This study has provided the impetus for the development and implementation of long-term, school-based nutrition education programs, on which we are currently working.

M.R. Neyman is Assistant Professor, Department of Biological Science, California State University, Chico; G. Block is Professor, School of Public Health, UC Berkeley; J. Morris was a Ph.D. Candidate and S. Zidenberg-Cherr is Nutrition Specialist, Department of Nutrition, UC Davis. The authors gratefully acknowledge the cooperation of the young women and teachers who participated in this study. We also wish to acknowledge Shaya Hamid, Laura
Minor, Janet Peerson, Cynthia SerraRabenstein and Kirin Tu for their technical assistance.

\section{References}

[CBDMP] California Birth Defects Monitoring Program. 1994. Birth Defects in California: 1983-1990. California Department of Health Services. Sacramento, CA.

DiSogra L, Abrams B, Hudes M. 1994. Low prevalence of healthful dietary behaviors in a California agricultural county: Emphasis on white and Mexican-American adults. J Am Diet Assoc 94:544-6.

Fanelli-Kuczmarski M, Wotecki CE. 1990. Monitoring the nutritional status of the Hispanic population: Selected findings for Mexican Americans, Cubans and Puerto Ricans. Nutr Today May/June:6-11.

Hall B, Richards F. 1995. 1994 Health Data Summaries for California Counties. California Department of Health Services, Sacramento, CA.

Halliwell B. 1996. Antioxidants. In: Ziegler EE, Filer LJ (eds.). Present Knowledge in Nutrition. 7th ed. Washington, DC: ILSI Press, $p$ 596-603.

[IOM] Institute of Medicine, Food and Nutrition Board. 1989. Recommended Dietary Allowances. 10th ed. Washington, DC: National Academy Press. $283 \mathrm{p}$.

IOM. 1999. Dietary Reference Intakes for calcium, phosphorus, magnesium, vitamin D and fluoride. National Academy Press. 374 p.

IOM. 2000a. Dietary Reference Intakes for thiamin, riboflavin, niacin, vitamin $\mathrm{B} 6$, folate, vitamin B12, pantothenic acid, biotin and choline. National Academy Press. 596 p.

IOM. 2000b. Dietary Reference Intakes for vitamin $C$, vitamin $E$, selenium and carotenoids. National Academy Press. $486 \mathrm{p}$.

Keen CL, Zidenberg-Cherr S. 1994.

Should vitamin-mineral supplements be recommended for all women with childbearing potential? Am J Clin Nutr 59:532S-9S.

Looker AD, Loria CM, Carroll MD. 1993. Calcium intakes of Mexican Americans, $\mathrm{Cu}$ bans, Puerto Ricans, non-Hispanic whites and non-Hispanic blacks in the United States. J Am Diet Assoc 93:1274-9.

[LSRO] Life Sciences Research Office. 1995. Third Report on Nutrition Monitoring in the United States, Executive Summary.

Washington, DC: U.S. Government Printing Office. Vol. 2. $323 p$

Posner BM, Morgan JL. 1992. The 2D Food Portion Visual. Framingham, MA: Nutrition Consulting Enterprises.

[USDA/USDHHS] U.S. Department of Agriculture and U.S. Department of Health and Human Services. 1992. Food Guide Pyramid. Home and Garden Bull. No. 252. Washington, DC: U.S. Government Printing Office. $29 \mathrm{p}$.

USDAUSDHHS. 1995. Dietary Guidelines for Americans. 4th ed. Home and Garden Bull. No. 232. Washington, DC: U.S. Government Printing Office. $43 \mathrm{p}$.

[USDHHS] U.S. Department of Health and Human Services. 1985. Report of the

Secretary's Task Force on Black and Minority Health. Vol I: Executive Summary. Washington, DC: U.S. Government Printing Office. $295 \mathrm{p}$. 